\title{
Managing intellectual property in the digital product market
}

\begin{abstract}
Leo J. Mullins
is the founder and Managing Director of the digital management company, Optimiser Pty Ltd. He was awarded successive bursaries by the University of South Africa for academic excellence. He now holds DAM patents and has been living and working in Australia since 1985. His previous roles include professional and corporate accounting. Leo is a management consultant specialising in the fields of accounting, e-commerce and Management Information Systems (MIS).
\end{abstract}

Keywords: measurement, metadata, appropriate to access, unique identity, rules, evidence

Abstract This paper explores the general nature of, and issues relating to, intellectual property stored and distributed in digital form, as well as some of the main implications for business managers and the information communication technology industry. It covers a number of topics, broadly:

- The fundamentals of digital management (DM)

- DM's relationship to digital asset management (DAM) and digital rights management (DRM)

- The impact of e-commerce on the law of contract and DM

- The inefficiencies inherent in traditional practices

- The need for management to improve administration of digital intellectual property

- The increasing commercial importance of DM

- General taxation, accounting and administration issues and their relevance to, and impact on, the evolution of digital intellectual property management are also introduced.

The intention of the paper is to:

- provide a better practical understanding of DM

- demonstrate DM's impact on future best management practice

- highlight the importance of DM's predicted contributions to the processes and commercial value of e-commerce markets.

\section{THE NEED FOR DIGITAL MANAGEMENT}

The fundamental reason for management, its raison d'être, is the protection and administration of assets. Its principal weapon is measurement. Without measurement, value cannot be ascertained, wastage cannot be eliminated, and wealth cannot be maintained. Assets are commodities. They are, by definition, valuable in themselves, as well as being the tools used by a business to create more value. Conversely, anything that incurs a cost to a consumer is an asset and, hence, expense is viewed as the consumption of assets.

Business processes for managing tangible assets are accepted worldwide, having developed over the last 600 years, and are designed to measure revenue against the cost of assets consumed. The bases of these processes are:

- identification

- custody

- measurement

- settlement.

General ledger accounting and Enterprise Resource Planning (ERP) systems have traditionally managed tangible assets using the double entry system, recording ownership and transactions through various functional modules that comply with Generally Accepted Accounting Practices (GAAPs). 
Intangible assets, however, have never been satisfactorily accounted for in the same way because of their incorporeal nature and the associated problems of measuring them.

However, though sometimes contentious, serious investment has been made in the attempt to manage and value them. For example, brands valued on the strength of marketing spend and sales potential, carried on a company's balance sheet as goodwill. Why is this not the same with digital assets and products?

True, the internet space and online marketplace are relatively new, but the underlying economics and commercial imperatives are as they ever were. In addition, capitalism has already fostered sophisticated accounting and legal systems that are mature enough to be able to contribute immediately and directly to progressing the digital world.

Now, 21st century ratios of intangible to tangible asset values are three to ten times higher than just a decade ago. Then, intangible assets comprised approximately $10-50$ per cent of the tangible asset value of an enterprise. Today it is likely that an enterprise's intangible assets are worth far more than its tangible assets.

Intangible asset values are growing faster and becoming more important than tangible assets. This trend can only continue as service economies become the norm with more and more associated activities provided via the internet.

This is solid evidence of the increasing importance of intangible assets, not just to corporate performance and wealth creation, but also as another layer of capital bedrock. Yet, no adequate system for managing and accounting for them has yet been developed.

According to the World Intellectual Property Organization's Report (WIPO) of November 2003:

Today DRM remains a fledgling industry ... Several initiatives ... promise to create a networked environment that is trusted, based on the secure identification of users, devices and software modules, ensuring that content can only be exploited in line with rules set by the owners of the material. ... However, this technology is still some way off (and, according to some, will never succeed) and for the moment, it is necessary to concentrate on specific technologies solely designed for the protection of intellectual property rights. ${ }^{1}$

The evidence and consequent effects of this situation are apparent in virtually every organization, given society's reliance on information technology.

Software, an example of a vendor's intellectual property, still has to be purchased outright. The costs are either written-off or amortized according to inadequate depreciation policies that assume the consumption rate of each asset to be the same.

When organizations create digital assets, there is usually no accounting for them at all when used internally. Consider any software company where its employees use its own product. Current accounting practice considers that the use of such assets cannot be correlated with revenue performance over time, and is without cost. Clearly this treatment is deficient.

Additionally, when digital assets are deployed externally, the intellectual property owner loses control. Consider an architect sending out plans for a tender, or the lawyer with client confidential communications, over email. Anything can happen to that email and its attachments once it has left the corporate network boundary.

The result is plain to see: no meaningful management or accounting for a digital asset's value, either created or consumed. Furthermore, what should be of concern to every business manager: no information for commercial decision making.

\section{DIGITAL MANAGEMENT AND THE LAW}

The basis for laws governing DM is essentially the same as that for traditional trading activities. Laws have evolved out of the need to exchange value between buyers and sellers, and technology has not changed these needs. What has changed is the ability of buyers and sellers to extend their geographic reach; increase their potential transaction volumes; and speed up their turnover rate.

This does not change any of the fundamental needs of trading for fairness, honesty, transparency, and reasonable terms for delivery and payment. However, the new capacity to trade digital intangibles requires that traditional 
trading law also be extended, to maintain its relevance and effectiveness in the electronic marketplace. The responsibility of the legal profession is to develop practical "cyber laws" to apply the accepted norms of commercial, contract and trading law to e-commerce.

\section{THE DIFFERENCE BETWEEN DIGITAL RIGHTS AND DIGITAL ASSETS (DRM V. DAM)}

The term "rights" is generally considered only from a legal perspective and the concept of ownership, with scant linkage to assets, revenues and costs.

Consequently, the traditional business of rights management is a legal one, aimed at excluding access to intellectual property by any party which does not have the legal capacity, or permission, to use or consume a specific asset. For example, the numerous litigations over trademark infringements online or otherwise.

The prevailing attitude of businesses towards so-called DRM seems to rely exclusively on the technical fraternity being able to protect digital content with technological wizardry. The hope seems to be on preventing unauthorized use before the event, as a complement to traditional rights managers - the lawyers who pursue remedy after the event.

Unfortunately, this myopic perception has been the template used by the information technology industry in its DRM efforts to date. Restricted largely to software licensing, DRM technology has failed because of its inability to deal with the intrinsic nature of digital product. Easy duplication of a digital asset provides consumers with almost infinite and cost-free access, without depriving original purchasers of their rights or utility.

Rights are seen solely as an enforcement issue, primarily through an overemphasis on encryption as the keystone to security. However, this offers no management capability beyond a "give access or deny" event when the asset is initially deployed, but even that has not been enforceable.

Conventional thinking, therefore, construes DRM as fundamentally concerned only with technology and processes, and has omitted commerce and management - or, in other words, value creation and preservation.
Digital asset management is generally considered to be the management of intangible digital assets. It is therefore focused on measuring and identifying, perhaps incorporating facets of DRM but essentially focusing on the "inclusive" aspect of managing digital intellectual property; in other words the measurement and recording of access and consumption of assets.

For the sake of completeness, however, it is also possible for a right to exist without creating value and thus not be considered an asset in immediate commercial or financial terms. This can happen where ownership of an entity can be clearly shown but no revenue streams or costs attach to it.

For example, a professor's draft research paper, distributed electronically among his or her peers for comment, prior to publication. While there is no immediate financial value and it is less relevant to commercial management, from a legal point of view, rights still attach.

Such intellectual property falls outside the scope so far considered as DAM, but would still warrant DRM to minimize infringement, as well as aid editing and withdrawal leading to publication.

The difference between DAM and DRM is significant but not generally fully understood or agreed on, and, in some cases, not even acknowledged.

Again, per WIPO's recent deliberations:

From a functional perspective, DRM means many things to many people. For some it is simply about the technical process of securing content in digital form. To others, it is the entire technical process of supporting the exchange of rights and content on networks like the internet. For convenience, DRM is often separated into two functional areas.

The identification of intellectual property, rights pertaining to works and to parties involved in their creation and administration (digital rights management): "DAM"

The (technical) enforcement of usage restrictions (digital management of rights): "DRM"2

\section{DIGITAL MANAGEMENT (DM)}

The term "DM" is now emerging to encompass all aspects of both DAM and DRM, since there 
is little point for one without the other in the commercial arena.

Given the growing role of intangible assets in today's businesses, combined with the necessary involvement of accountants and commercial managers in the relatively new digital intellectual property value chains, the need to properly account for intangible assets is rapidly moving front stage and center.

So DM is necessarily about meeting the identified need to account for, and protect, the creation, storage, distribution, access and control of intangible assets in digital form, wherever and whenever they are found or consumed. It has to develop, and quickly, to provide the full spectrum of fiduciary and management control.

The four cornerstone concepts, in well-known terms, are:

- ownership

- security

- accounting

- e-commerce/e-banking.

To be truly effective, DM should enable contract; the setting of terms and conditions of both use and access. Vitally, to properly manage a digital asset or product, DM needs to be dynamic and flexible to permit alteration to any aspect of control over an asset after its deployment, preferably without being constrained by connectivity issues. So far there has been little or no success in this area.

The most effective way to provide an efficient, publicly available, DM system is via the internet using web service technology. A DM web interface, accessible to buyers and sellers of digital assets, should allow both negotiation and the exchange of value. It must support the set-up of legal agreements and their terms, and consequent deployment, in real-time. The system will then technically enforce rights such that contracts cannot be breached, with any hacking attempts resulting in the destruction or disablement of the product.

Digital management must also meet the needs of management by providing software, infrastructure, data, and reporting functionality to digital asset owners and managers irrespective of their physical location.

The benefits of a well-designed DM system are improved management and administration of intellectual property leading to:
- revenue security

- lower costs of software application and content administration

- acquisition of product usage information.

In short, an infrastructure platform for accounting, billing, product development, technical support, sales, marketing, and innovative customer service.

Digital management services must establish terms of use in e-contracts between product suppliers and customers, and these must be evidenced by all relevant parties on the system. These contracts form the basis of the security needs of a digital product when it is deployed, and should be continually monitored for conformance and compliance by the system.

Corporate governance would be well-served by efficient DM that securely ensured enforcement of all contract terms and conditions of deployment, and use of an owner's digital intellectual property. Usage data also lend themselves to digital product procurement to help prevent overspending on software and content, a common problem for corporate management.

Digital management also needs to be supported by standards covering interoperability needs of all types of rights-holders in the digital environment.

The European Commission's INFO 2000 Programme indecs Report, June 2000, identifies four guiding principles of any DM framework for supporting effective e-commerce, namely:

- Unique Identification - every entity should be uniquely identified within a unique namespace

- Functional Granularity - it should be possible to identify an entity whenever it needs to be distinguished

- Designated Authority - the author of an item of metadata should be securely identified

- Appropriate Access - everyone requires access to the metadata on which they depend, as well as privacy and confidentiality for their own metadata from those who are not dependent on them.

The requirements of a successful DM technology would also be expected to include:

- No single points of failure such that loss of internet connectivity will not interrupt DM 
services or prevent users from accessing digital assets or products to which they are entitled

- universally availability of control over DM and administrative settings, and reporting tools, via the internet

- integration of application usage information with ERP/accounting, billing, and payment systems

- little or no infrastructure impositions on existing IT environments.

A good DM system must meet the needs for administering digital asset delivery on a world scale. It thus requires secure communications and these are now possible over the internet.

The already huge and rapidly growing market for intellectual property, and the internet globalization of business, require that successful DM systems interoperate and scale to millions of transactions, definitely by the hour, most probably by the second.

To be really effective, any DM service would scale easily to support the development and operation of a global system, with confidential data collection by a secure, real-time update and backed-up database. The database would meet the intellectual property reporting and accounting needs of managers.

Moreover, from macro to micro, individual user needs must be met or the DM system will simply not be used. DM must have rich functionality and flexibility to cater to the interest of all rights-holders by managing legal and licensing structures - past, present, and future.

\section{TRADITIONAL DEPLOYMENT PROCESSES AND LICENSE MANAGEMENT}

An important aspect of DM will be its replacement of traditional licenses and license management regimes for software distribution. This, however, by no means diminishes the need for licensing. It is instead a necessary evolution along true Darwinian lines, through nearspontaneous mutation when comparing the respective lifespans of tangible asset management practices and the still young internet.

Extrapolating the conclusion of a recent study of the development of the "real world," or contemporary tangible economy, it is a matter of economic survival:
The basis of capitalism ... is capital, and the basis of capital as an economic tool is rational property law. Without a complex system to delineate and protect rightful ownership, capital is "dead.",

The software industry continues to offer its product on a "boxed" or "seat license" basis. In the main, this is an inefficient and costly model for both vendor and user. These inefficiencies are particularly easy to identify in complex environments where there is periodic workflow, or project work. Expensive software, needed for short spells, remains idle and unused for a significant proportion of the time. Commercial pragmatism dictates that consumers impose restrictions on the number of costly licenses they acquire, resulting in too few copies during peak activity and too many once work is complete.

Investment-wise, software procurement decisions are often made without any empirical evidence of value to the purchasing enterprise, especially when renewing maintenance contracts. This contributes to higher than necessary corporate software costs through overbuying.

The traditional distribution model is estimated to cost software users, in wasted capacity, administration and underused assets, a significant percentage of their software purchase and maintenance costs.

These inefficiencies also impact software sellers. Organizations needing software generally conduct lengthy, albeit inadequate, capital evaluations before they acquire. The result is longer selling cycles, expensive sales processes, and higher prices. Higher prices cause acquisition decisions to be forced up management hierarchies, making purchasing decisions the victim of corporate politics.

Further, the process of software evaluation before purchase has spawned the "evaluation copy." This can add to distribution costs and increased risk of revenue leakage as producing evaluation software is expensive, has to be administered, and often, actively reduces revenue as customers capture software value without purchase. Many a project has been completed using a 30-day trial.

Another problem attributed to boxed product or seat license is the failure of vendors to develop education and training as a sales tool. Long sales cycles cause management to focus on corporate 
sales and marketing activities at the expense of educational activities with actual users. Smaller user bases and poorer user capability, in turn, result in less than optimum value received by both parties.

It is now evident that the capabilities are there for "pay as you use" sales models to be effectively employed, similar to those already making a success of the telecommunications services sector.

There are no valid reasons why software deployment cannot include all means to globally manage all commercial terms of use in real-time. Software and digital content access can now be negotiated, concluded, and administered online, in a real-time or near real-time electronic trading environment.

New web services with functionality for flexible, dynamic, and transparent transaction interfaces, providing secure and automatic enforcement of agreed software usage contracts, are rapidly changing the global e-commerce environment.

\section{ADMINISTRATION}

Distribution administration has always been a core aspect of corporate management. The internet has simply introduced an additional electronic delivery mechanism to the product deployment armory. This has increased the ability of all companies to deliver digital intellectual property on a global scale. Vastly larger revenue opportunities are created, but a corresponding set of challenges arise.

These challenges predominantly relate to administration and compliance issues in accounting, tax, and legal legislation, governing the different locations to which product is delivered. Smaller companies find these challenges harder to overcome than larger companies because the latter usually have experience of, and resources for, business conducted over multiple locations, and often countries, prior to their exposure to electronic trading systems.

The internet, while a great leveler on many fronts, does not reduce administrative need at the moment. However, this is precisely because fully-fledged DM systems do not exist and there is a deficiency in the offerings of the technology sector for comprehensive, easily integrable, international compliance systems.

\section{YET ANOTHER GROWTH SECTOR ON THE HORIZON}

\section{Taxation}

All governments collect money from their citizens, with taxes levied on commercial activities subject to relevant legislation and judicial boundaries. To fund public infrastructures and institutions, and support the living standards of the people, the highest value categories of taxes are generally those on trading profits, sales revenues, and custom duties.

Governments seek to influence the commercial activities of their citizens by varying rates of different taxes and granting concessions for defined activities. This creates the opportunity for business managers to reduce statutory liabilities by designing corporate structures and commercial transactions with taxation in mind.

These structures and transactions move tax crystallization points to coincide with lower tax rates and available concessions. Much of this activity involves the shifting of revenue streams between jurisdictions by transfer-pricing between corporate entities. In response to tax management activities, governments, in turn, enact more complicated legislation to protect their revenues.

Consequently, business managers are now faced with significant administration and reporting requirements imposed on them by legislation. This is not peculiar to digital products, applying equally to all business.

However, a particularly onerous obligation is going to be placed on digital product distributors. This is the obligation to collect tax on behalf of governments in each jurisdiction in which tax liabilities are incurred. The breadth of digital product markets means digital asset managers must now comply with the legislative requirements of every jurisdiction where they are deemed to operate. In other words, they will act as tax collectors in as many regimes as their transactions are seen to fall.

The operation of different tax systems, different rates, different compliance requirements, as well as different legal systems with their own interpretation of contract, makes the task faced by an administrator of a widely distributed digital product daunting in the 
extreme. In fact, without a comprehensive DM system it is difficult to comprehend how these needs can be met.

\section{Accounting}

In common with all products, digital delivery requires sales and marketing to communicate the value and benefit to customers. This requires infrastructure and resources to be effective. If a company does not possess these, it is forced to acquire them.

When third parties become involved in the digital delivery process the problem of accounting for contributions to the business effort, and share of resulting proceeds, becomes a serious matter.

Other issues include the transfer of ownership between digital product owners, third party distributors and customers, and the corresponding responsibility for warranties and support obligations. Digital asset owners have to address control issues of their product outside their own controlled business environs. These particularly relate to the exercise of adequate standards for accurately recording accrued revenues generated by agents on their behalf in far distant lands.

The inability to record access to, and log use of, digital product also impacts customers. Consumers of the asset generally have no means of measuring the ongoing internal cost or value of its use by, and within, their organization.

This lack of adequate accounting control over deployed digital products is a major problem for digital asset managers and is becoming increasingly important as the value of digital assets to businesses grows. DM technology development is largely being driven by the need to overcome these problems.

\section{CONCLUSION}

Digital management, properly developed, will introduce another badly needed dimension to the business of buying and selling intellectual property in digital form. It will solve the problem of not being able to securely deploy product and successfully account for it.

It will do this by moving responsibility from the technical programmer, where it should not be, and giving it squarely to the business manager where it should be. Thus, new capabilities arise for collection and analysis of relevant data for new business models and sales channels. In other words, increased revenues and higher efficiencies for all.

Digital management offers tremendous benefit to companies seeking to expand their geographic market without having to make the corresponding investment in administration that global distribution requires.

Digital management revolutionizes accounting and administration of all the economic and commercial aspects of digital intellectual property. It is especially beneficial to small technology companies developing high value intellectual property suitable for digital delivery which requires access to far distant larger markets, as commonly experienced by Australian enterprises.

As a catalyst for new associated businesses, DM is also beginning to create a demand for specialist paralegal/accounting services to advise intellectual property creators and owners on how best to get to market.

These services will assist clients in:

- meeting improved digital asset deployment goals

- development and analysis of selling models

- optimum pricing levels and selling strategies

- treasury and accounting administration

- global tax compliance and statutory obligations

- billing and collection services via payment and banking portals

- automatic integration of e-commerce and ebanking transactions with financial accounting systems.

These services will be a boost in the arm for the professions. Or a new one in the making?

For information technology itself, DM will benefit the industry directly and considerably, since the software sector is by far the largest producer and seller of digital assets. In turn, these are used by customers to produce their own digital assets, in other words, content. Both parties can only increase their profits and margins over the long term, through more flexible pricing models for both increasing revenues and reducing costs.

Efficient as it is in rolling out new versions of applications, no industry in history has been able to maintain such growth without providing the means to properly measure the claimed benefits of its product. Given Moore's Law and the interdependency of software applications within 
commercial environments, customers are becoming increasingly resentful at having to upgrade sites completely when, in some cases, a single vendor puts out a new release.

More cynically, some customers have started to believe that software vendors act deliberately to create the knock-on effect so the industry as a whole can boost its revenue for a particular period.

The latest BSA Global Software Piracy Study, carried out by IDC in July 2004, computed the global cost of software piracy to be more than US\$28bn in 2003, and rising due to the increasing popularity of broadband services. Even discounting some of the self-serving assumptions used in calculating total market values for deriving the number of pirated installations, this is of epic proportions.

It also starkly illustrates a growing phenomenon: the industry's perceived value of itself and its product is diverging dramatically from that perceived by its customers and endusers.

Moreover, the same study recognizes that piracy affects many, from the individual salesperson and their commission, through to the growth rates and potential of so-called developing economies. The latter can only become of increasing concern to institutions such as the World Trade Organization and United Nations, to name but two.

Given that the software industry is effectively mature, technology is a ubiquitous component of virtually everything the world uses, and that the industry prides itself on making everyone's life more productive and efficient, the honeymoon period is over and the writing is on the wall. Users of digital assets will pay-as-theygo and demand quality information for making their purchasing decisions. Effective digital management technology is not a "nice-to-have" but now an essential layer of modern business.

\section{References}

1 Cunard, J., Banlas, C. and Hall, K. (2003)

"Report on current developments in the field of digital nights management," World Intellectual Property Organization, Geneva, November.

2 Ibid.

3 De Soto, H. (2000) The Mystery of Capital: Why Capitalism Triumphs in the West and Fails Everywhere Else, Basic Books, New York, NY. 